\title{
Normal Concrete Mix Design based on the Isoresponse of Slump as a Function of Specific Surface Area of Aggregate and Cement Paste-Aggregate Ratio
}

\author{
Nabil Dhiya Ulhaq ${ }^{1}$, Relly Andayani ${ }^{1 *}$ \\ ${ }^{1}$ Department of Civil Engineering, Faculty of Civil Engineering and Planning, Gunadarma University, Depok \\ 16424, Indonesia
}

\begin{abstract}
Many methods of normal concrete mix design produce the same proportion of cement and water content of concrete for different specific surface area of aggregate. Therefore, they often produce inappropriate workability of fresh concrete in the first batch. In the end, several trial batch adjustments are required by increasing or decreasing cement paste for reaching the required slump. This research aims to find out the correlation between specific surface area of aggregate and cement paste-aggregate ratio (C/A) to slump in a constant water-cement ratio $(\mathrm{W} / \mathrm{C})$ in normal concrete. This correlation will be used as an alternative method of normal concrete mix design. First, the new fine aggregate was established by modifying natural fine aggregate gradation. Then, two reference mixtures with these natural and modified fine aggregates were designed based on SNI 03-28342000. From each of these mixtures, the water content was added and reduced at multiple of 10 $\mathrm{kg} / \mathrm{m}^{3}$ in a constant water-cement ratio until the measured slumps of samples had approached or reached 6 and $18 \mathrm{~cm}$. Thus, different specific surface area of aggregate, cement paste-aggregate ratio, and slump could be known. Then, an isoresponse is developed to present the correlation between these variables. Finally, other mixtures are designed based on this isoresponse to validate it. The isoresponse is considered satisfactory if the measured slump of the validation mixtures does not deviate more than $2 \mathrm{~cm}$ of the required slump. The result shows that the measured slumps of validation mixtures had maximum deviations of $1 \mathrm{~cm}$ only. It means that the isoresponse of slump as a function of specific surface area of aggregate and cement paste-aggregate ratio can be used to predict the slump of a mixture and also as an alternative method of normal concrete mix design.
\end{abstract}

Keywords: Cement paste-aggregate ratio; Isoresponse; Normal concrete mix design; Slump; Specific surface area of aggregate

\section{Introduction}

Concrete is a favoured building material due to its ease of production and use (Han et al., 2016). Along with the increasing use of concrete as a building material, concrete improvement was also carried out by researchers in the past few years. One way to improve concrete mixtures is to do experimental research about the possibility of using other concrete constituents as additives or substitutions. For example, Yadav et al. (2018) that have conducted research on high range replacement of normal aggregates with recycled aggregates. Likewise, Eddhie (2017) developed mathematical equations that account for the relationship between the content of nanosilica and the mechanical properties of concrete so it can be applied to any concrete mixture. The improvement of concrete mixtures can also 
be done by finding the influence of various variables and their correlation that affect the properties of fresh and hardened concrete.

Amini et al. (2019) have investigated the relationship between paste ingredients for achieving an optimum paste-to-void volume ratio to meet given performance requirements. Curing as a variable that affects the properties of concrete has also been taken to the next level, Nie et al. (2016) explored the internal curing as a way of overcoming the disadvantages associated with heat curing and for improving the performance of heatcured concrete. Another way to improve concrete mixtures is by developing optimum proportioning of concrete. In this case, the new method of concrete mixtures design can also be developed. Yeh (2007) applied analytical methods by using Computer-Aided Design system to search for the optimum mixture of concrete composition. Moreover, Yong et al. (2018) have developed a new method of high-performance concrete mixture design based on the 4-parameters compressible packing model of Packing Density Theory. Ahmad and Alghamdi (2014) also conducted a statistical analysis of experimental data and developed mathematical polynomials regression to obtain an approach in the optimum proportioning of concrete mixtures. Actually, there is a possibility that there are other ways to improve the concrete mixtures besides those already mentioned. The point is how this concrete mixtures improvement produces concrete that is more satisfying. One factor that shows concrete satisfaction is workability and it can be influenced by many variables such as the specific surface area of aggregate.

ACI (2008) 238.1R-08 explains that the specific surface area of aggregate is a derivative of the factors that affect the workability of concrete. Hughes (1973) explained that the specific surface area of aggregate can represent the gradation of an aggregate as a single numerical value or commonly known as grading modulus. It can be calculated by simplifying the specific surface area of aggregate as the surface area per unit volume of spheres which pass the same sieve sizes as the actual aggregate. Moreover, other methods for quantifying the specific surface area of aggregate have developed in recent studies, such as using imaging techniques, developed mathematical models, Brunauer-Emmett-Teller model, etc. (Rabbani et al., 2014; Panda et al., 2016; Zhang and Luo, 2018). Tattersall (1991) explains that specific surface area of aggregate is the ratio of the total surface area to the total mass or volume, and is measured in $\mathrm{m}^{2} / \mathrm{kg} \mathrm{or} \mathrm{m}^{2} / \mathrm{m}^{3}$. In concrete, this means that the area of surface to be coated and lubricated by finer particles and by cement paste is greater and thus, other things being equal, it would be expected that the finer the fine aggregate, the less workable the concrete.

However, there are many mix design standard methods that do not accommodate specific surface area of aggregate as a variable that influence concrete. SNI 03-2834-2000 and IS 10262:2009 as standard methods in concrete mix design in Indonesia and India classify fine aggregate gradations into four grading zones. Moreover, the results of mix design will produce the same proportion of water and cement content for specific grading zone and required slump. However actually, all fine aggregates classified into the same grading zone can have specific surface areas of aggregate that are very different from each other. In British method which was presented by Teychenné et al. (1997), the proportion of fine aggregate is determined based on the percentage of fine aggregate that passes 600 $\mu \mathrm{m}$ sieve. In fact, even though there are two fine aggregates with the same percentage of $600 \mu \mathrm{m}$ of sieve passing, they likely have very different specific surface areas of aggregate. In ACI (2002) 211.1-91, the fineness modulus of fine aggregate determines the proportion of coarse and fine aggregates in a mixture. However, the fineness modulus actually cannot describe the specific surface area of aggregate. In this case, it is possible for two fine aggregates to have the same fineness modulus but actually, they have different specific 
surface areas of aggregate. Likewise, for SNI 7656:2012 which is an adoption of ACI (2002) 211.1-91 and is the most recent standard method in concrete mix design in Indonesia. In the end, concrete mixtures that were designed using those standard methods require several trial batch adjustments by increasing or decreasing cement paste for reaching the required slump.

In the present study, the effort has been made by changing the value of cement pasteaggregate ratio (C/A) of concrete mixtures. These changes will affect the value of the specific surface area of aggregate and slump of concrete mixtures. Thus, the correlation between specific surface area of aggregate, cement paste-aggregate ratio, and slump can be presented in the form of an isoresponse, or what can be known as a contour plot. Sonebi (2004) has also used isoresponse to present the relationship of several variables in concrete, such as W/C, cement content, slump flow, fluidity loss, compressive strength, et cetera. This is because isoresponse is very easy to present relationships between three or more variables in one form. Finally, from the isoresponse developed in this study, it is expected that the measured slump of a concrete mixture can be predicted. Furthermore, this isoresponse is also expected to be used as a new method of normal concrete mix design.

\section{Experimental Setup}

\subsection{Research Methodology and Limitations}

The research methodology will be explained in Figure 1 below.

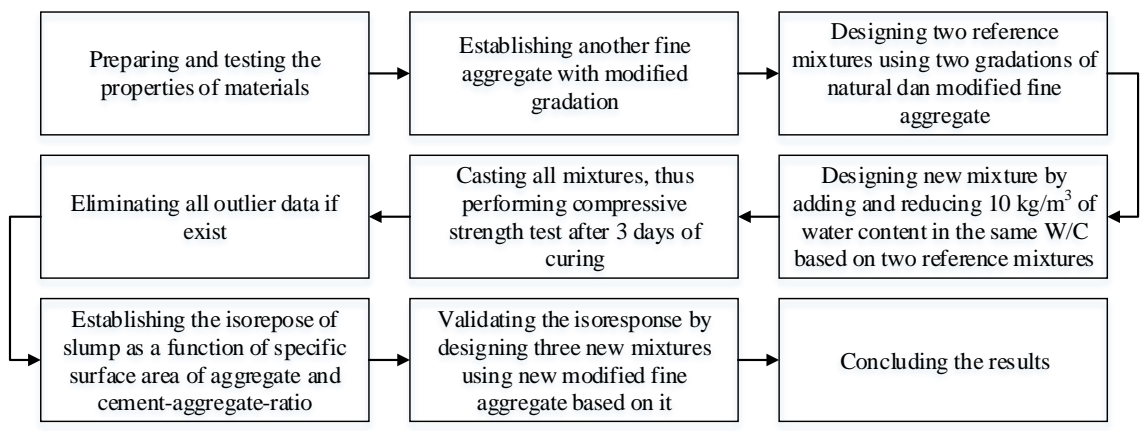

Figure 1 The research methodology

The Indonesian National Standard (SNI) was used as standard test method and specification in this study. This standard covered all procedures for testing materials and concrete and their specifications. Moreover, SNI 03-2834-2000 was used as the main concrete mix design method in this study and it has the main purpose in designing two reference mixtures as initials.

These reference mixtures will be designed using fine aggregate with two different gradations which are classified into two different grading zones according to SNI 03-28342000. For example, there is a natural fine aggregate that has a gradation classified into one of the grading zones. Then, the modified fine aggregate will be made from it, thus it has new gradation classified into a different grading zone than before. This can be obtained by adding several gradation fractions of the natural fine aggregate with certain proportions. Thus, the cumulative percentage passed for each faction will change as desired and so will the grading curve.

Furthermore, other mixtures will be designed based on both reference mixtures by adding and reducing water content in multiples of $10 \mathrm{~kg} / \mathrm{m}^{3}$ in a constant water-cement ratio, thus the proportions will change entirely. This change will also cause changes to the 
specific surface area of aggregate and cement paste-aggregate ratio and it is estimated that the slump will also change.

The number of specimens is considered sufficient if there is measured slump of the mixtures that has approached or reached $6 \mathrm{~cm}$ and $18 \mathrm{~cm}$. This is the required range of slump in SNI 03-2834-2000 that has been chosen and this is one of the limitations in this study. Data with measured slump that is far different from the required range of slump of $6-18 \mathrm{~cm}$ will not be used and it is considered that the proportion should be designed with other required range of slumps, not $6-18 \mathrm{~cm}$.

All mixtures will be designed for K300 grade concrete with water-cement ratio of 0.505 . Therefore, the compressive strength test is done to find out whether all the mixtures meet the required grade or not. This test is also needed to find out the existence of extreme values or outliers. If there are compression strength data that deviate so far from the others, they are classified as outliers and should be removed from the analysis.

In the end, the isoresponse will be developed and then validated by three new mixtures to ascertain whether it can be used as an alternative method of normal concrete mix design or not. These validation mixtures will be designed with the same method as all specimens with required slump of 8,12 , and $16 \mathrm{~cm}$. However, the fine aggregate for these mixtures has new gradation that is different from all specimens. If the measured slumps of these three mixtures deviate more than $2 \mathrm{~cm}$ from the required/predicted slump, this isoresponse is considered not to be used to predict the slump of a mixture and as an alternative method of normal concrete mix design, and vice versa.

\subsection{Material Properties}

Portland composite cement and water as cement paste in concrete mixture were used in this study. The Portland composite cement has Semen Tiga Roda as its trademark and its specific gravity was 3.15. Moreover, the water which was used as a mixture of concrete is ground water in Ciracas area, Jakarta Capital Special Region and it has specific gravity of 1.

Quartz sand from Bangka and crushed aggregate from Bogor, Indonesia, was used as fine and coarse aggregate in this study. Bangka sand has specific gravity (SSD) of 2.609 and absorption of $0.87 \%$. As explained above, this fine aggregate will be made into two different gradations based on the grading zone classification in SNI 03-2834-2000. Its natural gradation is classified into grading zone 2 and the gradation of modified one is classified into grading zone 1 as shown in Figure 2.

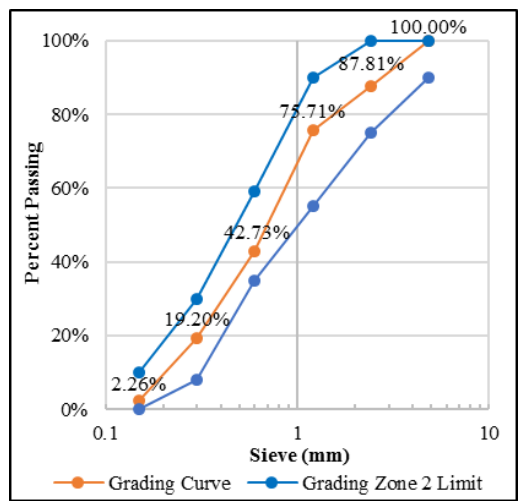

(a)

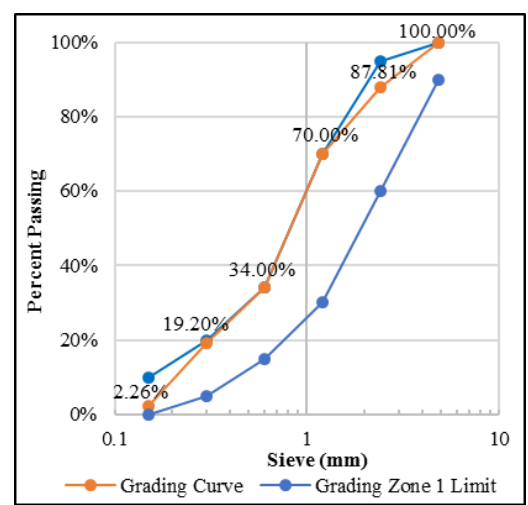

(b)

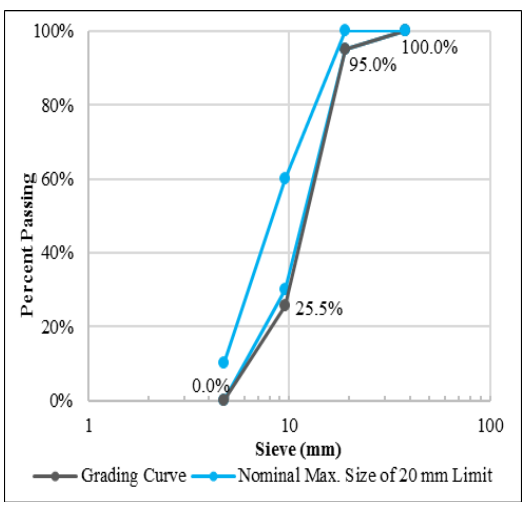

(c)

Figure 2 (a) Grading curve of natural fine aggregate and grading zone 2 limit; (b) grading curve of modified fine aggregate and grading zone 1 limit; and (c) Grading curve of coarse aggregate and nominal maximum size of $20 \mathrm{~mm}$ limit

Meanwhile, the coarse aggregate has specific gravity (SSD) of 2.594 and absorption of 
$2.27 \%$. Moreover, it could be known that it had nominal maximum size of $20 \mathrm{~mm}$ based on SNI 03-2834-2000 as also shown in Figure 2.

\subsection{Specimen Mix Design}

The specimens in this study consist of two reference mixtures and other mixtures that have been modified refer to these two reference mixtures. It is important to note again that it is unknown how many specimens are needed. The number of specimens is considered sufficient if there is measured slump of both reference mixtures of the modified mixtures that has approached or reached $6 \mathrm{~cm}$ and $18 \mathrm{~cm}$. Table 1 shows the mix design of all specimens.

Table 1 Specimen mix design

\begin{tabular}{|c|c|c|c|c|c|c|c|}
\hline \multirow{2}{*}{ Specimen* } & \multirow{2}{*}{$\begin{array}{l}\text { Fine Agg. } \\
\text { Grading Zone }\end{array}$} & \multirow{2}{*}{$\mathrm{W} / \mathrm{C}$} & \multicolumn{2}{|c|}{$\begin{array}{l}\text { Content of Binder } \\
\left(\mathrm{kg} / \mathrm{m}^{3}\right)\end{array}$} & \multirow{2}{*}{ S/A } & \multicolumn{2}{|c|}{$\begin{array}{l}\text { Content of Aggregate } \\
\qquad\left(\mathrm{kg} / \mathrm{m}^{3}\right)\end{array}$} \\
\hline & & & Water & Cement & & Fine Agg. & Coarse Agg. \\
\hline $\mathrm{N}$ & 2 & 0.505 & 225 & 445 & $41.5 \%$ & 686 & 961 \\
\hline $\mathrm{N}+10$ & 2 & 0.505 & $225+10$ & 465 & $41.5 \%$ & 669 & 937 \\
\hline $\mathrm{N}+\mathrm{XX}^{* *}$ & 2 & 0.505 & $225+X X$ & Adjusted & $41.5 \%$ & Adjusted & Adjusted \\
\hline $\mathrm{N}-10$ & 2 & 0.505 & $225-10$ & 426 & $41.5 \%$ & 704 & 986 \\
\hline $\mathrm{N}-\mathrm{XX}^{* *}$ & 2 & 0.505 & $225+X X$ & Adjusted & $41.5 \%$ & Adjusted & Adjusted \\
\hline M & 1 & 0.505 & 225 & 445 & $51.5 \%$ & 851 & 797 \\
\hline$M+10$ & 1 & 0.505 & $225+10$ & 465 & $51.5 \%$ & 830 & 777 \\
\hline $\mathrm{M}+\mathrm{XX} \mathrm{X}^{* *}$ & 1 & 0.505 & $225+X X$ & Adjusted & $51.5 \%$ & Adjusted & Adjusted \\
\hline M-10 & 1 & 0.505 & $225-10$ & 426 & $51.5 \%$ & 873 & 818 \\
\hline$M-X^{* *}$ & 1 & 0.505 & $225+X X$ & Adjusted & $51.5 \%$ & Adjusted & Adjusted \\
\hline
\end{tabular}

${ }^{*} \mathrm{~N}$ refers to mixture with natural fine aggregate and $\mathrm{M}$ refers to mixture with modified fine aggregate

${ }^{* *}$ The symbol of XX means the amount of addition or reduction of water content in multiples of $10 \mathrm{~kg} / \mathrm{m}^{3}$

\subsection{Mixing, Casting, and Curing Procedure}

Mixing, casting, and curing all specimens in this study refer to SNI 2493:2011. Hand mixing is the procedure chosen in batch mixing of all specimens rather than machine mixing. Machine mixing procedure causes a large amount of mortar is lost because it attaches to the inner side of the drum thus it is feared that it will affect the value of the slump later. The batch mixing process will be three times for each specimen. Moreover, for each batch mixing, it will be 13.5 liters of fresh concrete for testing the slump and casting three $15 \times 15 \times 15 \mathrm{~cm}^{3}$ cubes of compressive strength test sample. Therefore, there are three samples of slump and nine samples of compressive strength for each specimen. Finally, all samples will be removed from the molds after hardened and will be placed in the water storage tank for three days before testing the compressive strength.

\subsection{Slump and Compressive Strength Test Method}

The slump test that will be used to determine the slump of fresh concrete mixtures refers to SNI 1972:2008. Since there will be three times of batch mixing, three measured slumps will be obtained for each specimen. This amount is quite reliable to describe the slump value of each specimen. Moreover, the compressive strength test of hardened concrete refers to SNI 1974:2011. Because there will be three compressive strength test samples for each batch mixing, thus there will be nine data of compressive strength for each specimen. 


\section{Results and Discussion}

\subsection{Specific Surface Area of Aggregate, Cement Paste-Aggregate Ratio, and Slump}

Table 2 below shows the specific surface area of aggregate, cement paste-aggregate ratio, and slump of each specimen. The number of specimens as many as 10 mixtures was considered sufficient because the measured slump was approaching or reaching $6 \mathrm{~cm}$ and $18 \mathrm{~cm}$. In addition, the specific surface area of aggregate was calculated based on the same assumptions as Hughes (1973) defined his grading modulus. Each aggregate particle is assumed to be a spherical shape with diameter of the average from the smallest sieve it passed and the biggest it retained.

Table 2 also shows that the addition and reduction of water content are not linear with the change in slump as described in ACI (2002) 211.1-91 and IS 10262:2009. In ACI (2002) 211.1-91, it is recommended to increase and decrease the water content by $2 \mathrm{~kg} / \mathrm{m}^{3}$ of concrete for each increase or decrease of $10 \mathrm{~mm}$ in slump desired for a batch trial. Meanwhile in IS 10262:2009, an increase by about 3 percent of water content for concrete with coarse aggregate and 25 to $50 \mathrm{~mm}$ slump range will increase slump by $25 \mathrm{~mm}$. However, in this study, the increase in slump would be greater for each addition of $10 \mathrm{~kg} / \mathrm{m}^{3}$ in water content. This is very interesting to discuss in the further research.

Table 2 Specimen properties

\begin{tabular}{|c|c|c|c|c|c|c|}
\hline \multirow{2}{*}{ Specimen } & \multirow{2}{*}{$\begin{array}{l}\text { Specific Surface Area } \\
\text { of Aggregate }\left(\mathrm{m}^{2} / \mathrm{m}^{3}\right)\end{array}$} & \multirow{2}{*}{$\begin{array}{l}\text { Cement Paste- } \\
\text { Aggregate Ratio }\end{array}$} & \multicolumn{4}{|c|}{ Slump (cm) } \\
\hline & & & 1 & 2 & 3 & Average \\
\hline $\mathrm{N}$ & $28,381,919$ & 0.578 & 11.00 & 11.00 & 11.00 & 11.00 \\
\hline $\mathrm{N}+10$ & $27,652,519$ & 0.620 & 12.50 & 13.00 & 13.00 & 12.83 \\
\hline $\mathrm{N}+20$ & $26,923,119$ & 0.664 & 14.50 & 15.00 & 15.00 & 14.83 \\
\hline $\mathrm{N}+30$ & $26,193,719$ & 0.710 & 17.50 & 17.00 & 18.50 & 17.67 \\
\hline $\mathrm{N}-10$ & $29,111,319$ & 0.539 & 7.00 & 7.50 & 7.50 & 7.33 \\
\hline M & $33,732,553$ & 0.578 & 8.00 & 8.00 & 8.00 & 8.00 \\
\hline$M+10$ & $32,865,644$ & 0.620 & 10.00 & 10.00 & 10.00 & 10.00 \\
\hline$M+20$ & $31,998,736$ & 0.664 & 12.00 & 12.00 & 12.50 & 12.17 \\
\hline$M+30$ & $31,131,827$ & 0.710 & 16.00 & 15.50 & 15.50 & 15.67 \\
\hline M-10 & $34,599,461$ & 0.539 & 4.50 & 4.50 & 4.50 & 4.50 \\
\hline
\end{tabular}

\subsection{Checking Outliers using Compressive Strength Data}

Because there are nine samples of compressive strength for each specimen, the total sample will be 90 mixtures for compressive strength test. Figure 3 shows the data distribution in boxplot and it can be seen that there are no outliers in these data.

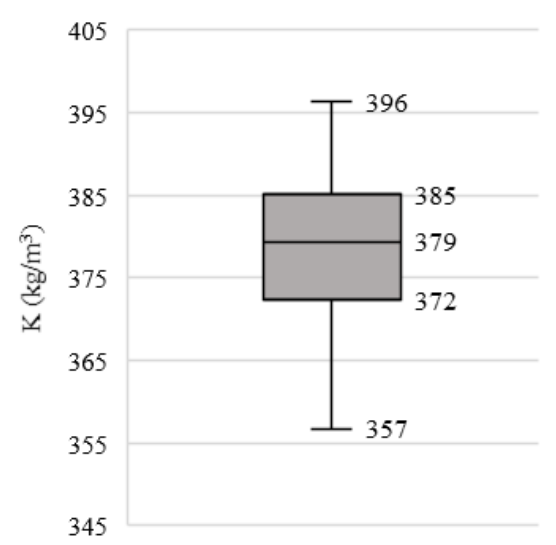

Figure 3 Boxplot of compressive strength data 
Therefore, there are no surface area of aggregate, cement paste-aggregate ratio, and slump data from the samples which are removed. The values mentioned in boxplots below respectively are the Minimum (Q0), Lower Quartile (Q1), Median (Q2), Upper Quartile (Q3), and Maximum (Q4).

\subsection{Correlation between Specific Surface Area of Aggregate and Cement Paste-Aggregate Ratio to Slump}

The correlation between specific surface area of aggregate and cement paste-aggregate ratio to slump is presented as isoresponse as shown in Figure 4. From this isoresponse, it can be seen that the greater the specific surface area of aggregate, the slump value will be smaller. This is in line with what is explained by Tattersall (1991), that the finer the fine aggregate (the greater the specific surface area of aggregate), the less workable the concrete. Conversely, the greater the cement paste-aggregate ratio, the slump value will be even greater. This is also in line with many other studies, for example Smeplass (1994) who found that an increase in cementitious materials content relative to aggregate volume resulted in a decrease in both yield stress and plastic viscosity thereby increasing concrete workability.

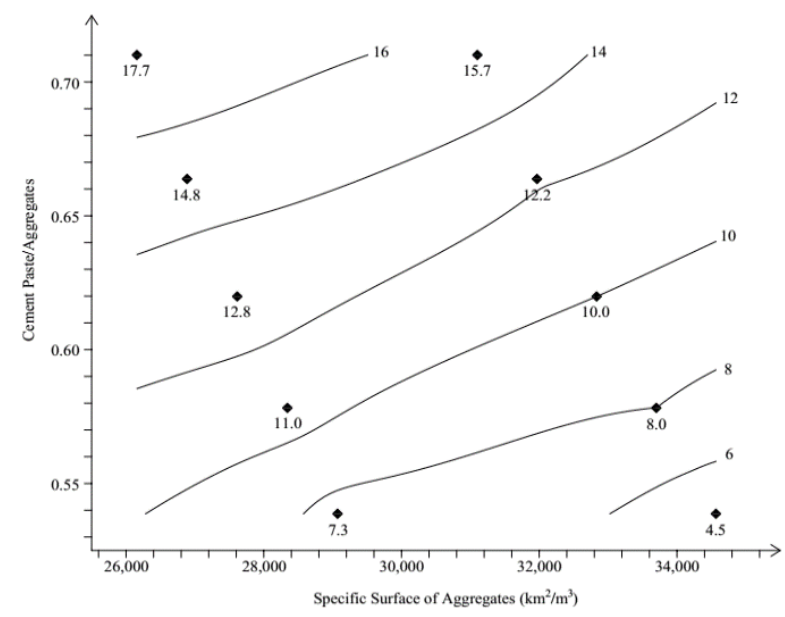

Figure 4 Isoresponse of slump as a function of specific surface area of aggregate and cement pasteaggregate ratio in water-cement ratio of 0.505

The interesting thing about the isoresponse developed in this research is that it offers a new concept in predicting slumps in a normal concrete mixture. This can be obtained by plotting the values of specific surface areas of aggregate and cement paste-aggregate ratio of a mixture to this isoresponse. However, a deviation between measured slump and predicted slump may occur. Therefore, the maximum deviation is set not more than $2 \mathrm{~cm}$ as explained in the research methodology above.

Furthermore, the isoresponse can be used as an alternative method of normal concrete mix design. For mixtures that required $\mathrm{W} / \mathrm{C}$ and slumps are already known, the proportion of aggregate and cement paste can be obtained by adjusting C/A and specific surface aggregate with this isoresponse. This is very effective, considering that many mixtures that are designed with other methods often do not get the required slump.

Although this isoresponse is limited to one $\mathrm{W} / \mathrm{C}$ value, the new concept offered is a new method that is simple and effective in predicting slumps and designing normal concrete mixtures. Moreover, as a prototype, developments can still continue to improve this method. 


\subsection{Validation}

Three validation mixtures were designed by using another new modified gradation fine aggregate, as shown in Figure 5 . The gradation of this new fine aggregate is made intentionally so that it can be classified into grading zone 1 and 2 according to SNI 03-28342000 or IS 383:2016 (note that the grading zone limits in these standards are the same).

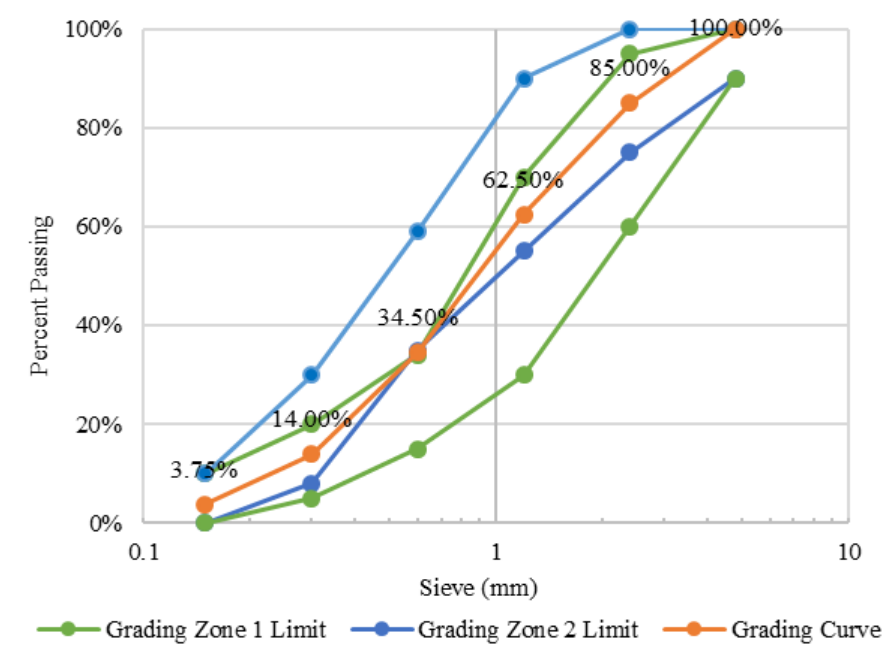

Figure 5 Grading curve of modified fine aggregate for isoresponse validation

The validation mixtures were designed based on the isoresponse, especially in determining water content for more specific required slump as shown in Table 3. It also shows the properties of these mixtures, which consist of specific surface aggregates, cement-aggregate ratios, and measured slumps. Whereas the plot results of the specific surface area of aggregate, cement paste-aggregate ratio, and slump of validation mixtures in the isoresponse are shown in Figure 6.

Table 3 Mix design and properties of validation mixtures with W/C 0.505

\begin{tabular}{lccc}
\hline \multirow{2}{*}{ Parameter } & \multicolumn{3}{c}{ Required Slump } \\
\cline { 2 - 4 } & $8 \mathrm{~cm}$ & $12 \mathrm{~cm}$ & $16 \mathrm{~cm}$ \\
\hline Mix Design & & & \\
Water Content $\left(\mathrm{kg} / \mathrm{m}^{3}\right)$ & 445 & 240 & 255 \\
Cement Content $\left(\mathrm{kg} / \mathrm{m}^{3}\right)$ & 686 & 475 & 505 \\
Fine Aggregate Content $\left(\mathrm{kg} / \mathrm{m}^{3}\right)$ & 660 & 633 \\
Coarse Aggregate Content $\left(\mathrm{kg} / \mathrm{m}^{3}\right)$ & 961 & 924 & 887 \\
& & & \\
Properties of Mixtures & & & \\
Specific Surface Area of Agg. $\left(\mathrm{m}^{2} / \mathrm{m}^{3}\right)$ & $32,003,090$ & $30,769,396$ & $29,535,703$ \\
Cement paste-Aggregate Ratio & 0.578 & 0.642 & 0.710 \\
Slump - Sample 1 (cm) & 9.0 & 12.5 & 15.5 \\
Slump - Sample 2 $(\mathrm{cm})$ & 8.5 & 11.5 & 15.5 \\
Slump - Sample 3 $(\mathrm{cm})$ & 7.5 & 13.0 & 16.5 \\
Average Slump (cm) & 8.33 & 12.33 & 15.33 \\
\hline
\end{tabular}

The slump values of each validation mixture are very close to the required slump as shown in Figure 6. It has no deviation except less than $20 \mathrm{~mm}$. Furthermore, it proves that the correlation between specific surface area of aggregate, cement paste-aggregate ratio, and slump which is presented in an isoresponse can be used as an alternative method in normal concrete mix design. Although, the isoresponse can only be used to design concrete 
mixture with water-cement ratio of 0.505 , however, this can be considered a prototype. For further research, to improve this prototype, it is very important to improvise various variables that affect slump, for example testing mixtures with variations in water-cement ratio, gradation, aggregate shape and texture, sand-aggregate ratio, et cetera. Other concrete mix designs may also be used as a main concrete mix design method other than SNI 03-2834-2000 for further research, for example ACI (2002) 211.1-91 or SNI 7656:2012 which are very different from SNI 03-2834-2000.

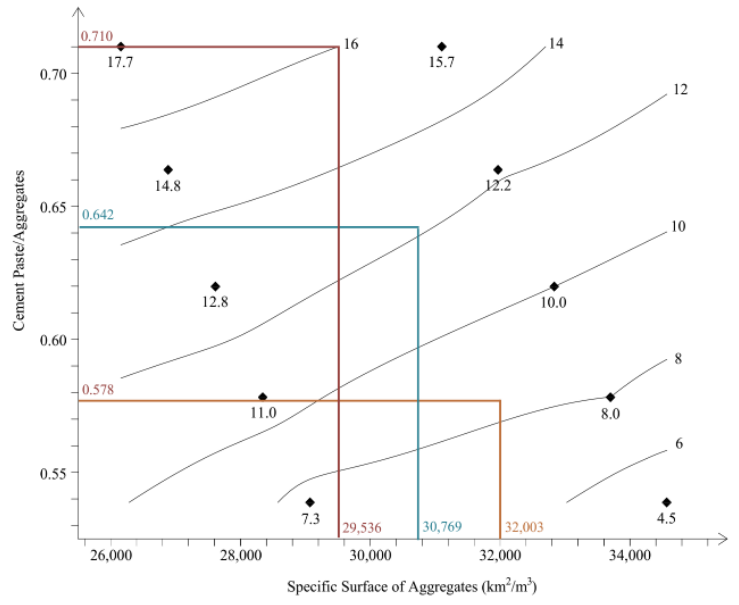

Figure 6 The Plot Results of the Specific Surface Area of Aggregate, Cement Paste-Aggregate Ratio, and Slump of Validation Mixtures $(\mathrm{W} / \mathrm{C}=0.505)$

Note that this alternative method might cause the cost of making concrete to be even greater for concrete with a higher required slump. This is because the amount of cement content needed will be even greater. Meanwhile, it is commonly known that portland cement is the most expensive concrete material among others. Therefore, it is recommended to use concrete mix design with superplasticizer admixture when designing concrete with a higher required slump.

\section{Conclusions}

Based on the experimental results in this study, the following conclusions have been drawn: (1) Indeed there is a correlation between specific surface area of aggregate and cement paste-aggregate ratio to slump which can be presented in an isoresponse. The greater the specific surface area of aggregate, the slump value will be smaller. Otherwise, the greater the cement paste-aggregate ratio, the slump value will be even greater; (2) From that correlation, a new alternative method of mix design has been developed. The advantage of this new alternative method is that a mixture of concrete with specific slump values can be designed. In contrast to the British Standard and Indonesian Standard methods which classify required slump in four ranges, which will complicate when designing concrete mixtures with slump values that are more specific; (3) In addition, a new method for predicting slump values of a concrete mixture also has been developed using that correlation. This method is a new thing because only by looking at the proportion of concrete materials and aggregate gradations, the slump value of the concrete mixture can be predicted without mixing the concrete and testing the slump before; (4) Improvements are still needed on these methods, it is recommended to examine variations in $\mathrm{W} / \mathrm{C}$ or other variables that can affect slump or other variables that can affect slump. 


\section{References}

ACI Committee 211, 2002. Standard Practice for Selecting Proportions for Normal, Heavyweight, and Mass Concrete (ACI 211.1-91 Reapproved 2002). American Concrete Institute, Farmington Hills, Michigan, USA

ACI Committee 238, 2008. Report on Measurements of Workability and Rheology of Fresh Concrete ( $A C I$ 238.1R-08). American Concrete Institute, Farmington Hills, Michigan, USA

Ahmad, S., Alghamdi, S.A., 2014. A Statistical Approach to Optimizing Concrete Mixture Design. The Scientific World Journal, Volume 2014, pp. 1-7

Amini, K., Vosoughi, P., Ceylan, H., Taylor, P., 2019. Effect of Mixture Proportions on Concrete Performance. Construction and Building Materials, Volume 212, pp. 77-84

Cement and Concrete Sectional Committee, 2009. Concrete Mix Proportioning - Guidelines (IS 10262:2009). Bureau of Indian Standards, New Delhi, India

Cement and Concrete Sectional Committee, 2016. Coarse And Fine Aggregate for Concrete Specification (IS 383:2016). Bureau of Indian Standards, New Delhi, India

Eddhie, J., 2017. Strength Development of High-Performance Concrete using Nanosilica. International Journal of Technology. Volume 8(4), pp. 728-736

Han, A., Gan, B.S., Pratama, M.M.A., 2016. Effects of Graded Concrete on Compressive Strengths. International Journal of Technology, Volume 7(5), pp. 732-740

Hughes, B.P., 1973. The Vebe Test and the Effect of Aggregate and Cement Properties on Concrete Workability. In: Fresh Concrete: Important Properties and Their Measurement: Proceedings of a RILEM Seminar, Leeds, England, 22-24 March 1973, Volume 2, pp. 4.31-4.3-12

Nie, S., Hu, S., Wang, F., Yuan, P., Zhu, Y., Ye, J., Liu, Y., 2016. Internal curing - A suitable method for improving the performance of heat-cured concrete. Construction and Building Materials, Volume 122, pp. 294-301

Panda, R.P., Das, S.S., Sahoo, P.K., 2016. An Empirical Method for Estimating Surface Area of Aggregates in Hot Mix Asphalt. Journal of Traffic and Transportation Engineering, Volume 3(2), pp. 127-136

Panitia Teknis Bahan Konstruksi Bangunan dan Rekayasa Sipil, 2012. Tata Cara Pemilihan Campuran untuk Beton Normal, Beton Berat dan Beton Massa (Standard Practice for Selecting Proportion for Normal, Heavyweight, and Mass Concrete) (SNI 7656:2012). Badan Standardisasi Nasional, Jakarta, Indonesia

Pusat Penelitian dan Pengembangan Teknologi Permukiman, 2000. Tata Cara Pembuatan Rencana Campuran Beton Normal (Standard Practice for Making Normal Concrete Mix Design) (SNI 03-2834-2000). Badan Standardisasi Nasional, Jakarta, Indonesia

Rabbani, A., Jamshidi, S., Salehi, S., 2014. Determination of Specific Surface of Rock Grains by 2D Imaging. Journal of Geological Research, Volume 2014, pp. 1-7

Sonebi, M., 2004. Applications of Statistical Models in Proportioning Medium-Strength SelfCompacting Concrete. ACI Materials Journal, Volume 101(5), pp. 339-346

Tattersall, G.H., 1991. Workability and Quality Control of Concrete. E\&FN Spon, London, England

Teychenné, D.C., Nicholls, J.C., Franklin, R.E., Hobbs, D.W., 1997. Design of Normal Concrete Mixes Second Edition. Building Research Establishment, Watford, England

Yadav, N., Deo, S.V., Ramtekkar, G.D., 2018. Workable and Robust Concrete using High Volume Construction and Demolition Waste in Sub Tropical Climate. International Journal of Technology, Volume 9(3), pp. 537-548

Yeh, I.C., 2007. Computer-Aided Design for Optimum Concrete Mixtures. Cement \& Concrete Composites, Volume 29, pp.193-202 
Yong, S., Zonglin, W., Qingfei, G., Chenguang, L., 2018. A New Mixture Design Methodology Based on the Packing Density Theory for High Performance Concrete in Bridge Engineering. Construction and Building Materials, Volume 182, pp. 80-93

Zhang, D., Luo, R., 2019. Modifying the BET Model for Accurately Determining Specific Surface Area and Surface Energy Components of Aggregates. Construction and Building Materials, Volume 175, pp. 653-663 